\title{
Mechanical Properties and Fatigue Performances on Sandwich Structures with CFRP Skin and Nomex Honeycomb Core
}

\author{
SEBASTIAN MARIAN ZAHARIA 1 , MIHAI ALIN POP2*, AUGUSTIN SEMENESCU³, BOGDAN FLOREA ${ }^{3}$, OANA ROXANA CHIVU 4 \\ ${ }^{1}$ Transilvania University of Brasov, Faculty of Technological Engineering and Industrial Management, Department of Manufacturing \\ Engineering, 5 Mihai Viteazu Str. , 500174, Brasov, Romania \\ ${ }^{2}$ Transilvania University of Brasov, Faculty of Materials Science and Engineering, Department of Materials Science, 1 Colina \\ Universitatii Str., 500084, Brasov, Romania \\ ${ }^{3}$ University Politehnica of Bucharest, Faculty of Material Science and Engineering, 313 Splaiul Independentei, 060021, Bucharest, \\ Romania \\ ${ }^{4}$ University Politehnica of Bucharest, Faculty of Engineering and Management of Technological Systems, 313 Splaiul Independentei, \\ 060021, Bucharest, Romania
}

\begin{abstract}
Composite sandwich structures with Nomex honeycomb core are commonly used in industrial applications. This paper was focused on the study of the mechanical properties of sandwich structures with CFRP (carbon fibre reinforced polymer) skin and a phenolic resin-impregnated aramid paper core, known as Nomex. The paper analyzes behaviour and determines the mechanical properties of the CFRP-Nomex specimens to different types of tests, such as: three - point bending, compression, impact. The exceptional fatigue resistance of the composite structures is responsible for their success in a variety of industrial applications. For this reason, in this paper were implemented accelerated testing techniques for CFRPNomex sandwich structures, resulting in a significant reduction of the test time (of 13.9 times). The main indicator that was determined using the accelerated testing methodology was the mean life that has value of 268554 cycles.
\end{abstract}

Keywords:sandwich structure, CFRP, Nomex honeycomb, accelerated testing, mean life

An optimized design in terms of aircraft weight requires them to be efficient in terms of fuel consumption and to present an increase in the payload accounting for the weight reducing syndrome [1]. This syndrome consists in using composite sandwich structures to allow the weight reduction of various components thereof increasing their performance.

Composite sandwich structures are widely used and allow obtaining this goal. Composite sandwich structures consist of two outer layers, called skins, united by a light core. The skins are subject to tensile and compression loads whereas the core resists the shear loads and supports the face sheets against buckling [2]. Sandwich structures present: low weight, good corrosion resistance [3,4], thermal resistance and excellent energy absorption capabilities [5], high stiffness-to-weight ratio, good buckling resistance [6] and good fatigue resistance.

The sandwich structure provides great versatility as a large range of core and skin material combinations can be chosen. The skins of sandwich structures can be made of various materials, such as plywood, aluminium alloy, titanium alloy, fibreglass, carbon fibre, Kevlar fibre [7]. Between the two skins can use the following structures core: wood (balsa, mahogany, fir, pine, spruce), honeycomb structure (paper, aluminium alloys, titanium alloys, copper alloys, nickel alloys, iron-based alloys, glass fibre, carbon fibre, kevlar or thermoplastics) and foams: expanded polymer foam, polystyrene foam, polyurethane foam [8]. In a sandwich structure, the resins and adhesives form the third structural component that unifies the core to the structure's skin.

In this paper was investigated the most widely used core for sandwich structure with multiple applications in the aviation field namely phenolic resin-impregnated aramid paper, known as Nomex (E.I. du Pont de Nemours Corp., Wilmington, DE, USA) [9]. Nomex honeycomb structure is recognized for: excellent electrical, thermal and fatigue properties; good formability; flame resistant; very good fire resistance and good insulating properties [2].

Applications of Nomex honeycomb core sandwich panels are encountered frequently in aviation for the following components: floors, doors, wing flaps, wing-body fairings, rudders, overhead stowage bins, ceiling or sidewall panels, engine cowls, spoilers, nacelles $[2,9]$. Recent studies have focused on Nomex honeycomb structure behaviour under: flatwise compression [10], compression properties after impact test [11], three - point bending test [12], bending-fatigue test $[13,14]$.

To be able to use these sandwich structures in various applications, knowing only their static properties still is not enough and needs more information on the phenomenon fatigue and fatigue life. This paper presents the results of an experimental investigation on the behaviour and performance in static and dynamic regime of the sandwich structures with skins made out of CFRP and Nomex honeycomb core. CFRP-Nomex sandwich specimens were tested in static regime for: three - point bending, flatwise compression and Charpy impact test and were determined the main mechanical characteristics (bending strength and modulus of elasticity, compressive strength and modulus of elasticity, impact strength). For the dynamic regime it was proposed a new methodology through which the testing regime sandwich structures is accelerated. Using this acceleration methodology it can be determined in a shorttime the fatigue life of the CFRP-Nomex sandwich specimens.

\footnotetext{
* email: mihai.pop@unitbv.ro
} 


\section{Experimental part}

Materials and methods

The CFRP-Nomex sandwich structure has two skins of carbon fibre fabric and Nomex honeycomb core. The CFRP-Nomex structure is made out of two carbon fibre plain weave style 282 skins with the prepreg resin content of $44 \%$. The CFRP-Nomex core structure consists of hexagonal Nomex honeycombs with the cell size and density being $5 \mathrm{~mm}$ and $48 \mathrm{~kg} / \mathrm{m}^{3}$. This structure which consists of two skins of carbon fibre prepreg and Nomex core assembly has been subjected to the hot pressing assembly process, resulting in a final thickness of the sandwich structure of $9 \mathrm{~mm}$.

\section{Three - point static bending test}

The specimens used in three - point static bending tests, were cut from CFRP-Nomex sandwich panel. Ten specimens were tested in three - pointbending, respecting the dimensions and the test procedure in accordance with ASTM C393. The three - point static bending tests were conducted on a WDW-150S universal testing machine and the crosshead speed was set to $3 \mathrm{~mm} / \mathrm{min}$. The sandwich specimens were placed on the supports (radius $R=6 \mathrm{~mm}$ ) with a distance of $120 \mathrm{~mm}$ between each other. The purpose of these tests was to determine the mechanical performance (bending resistance, bending modulus of elasticity and other aspects linked to the effort deformation relationship) of the sandwich structures fabricated. Table 1 describes the main dimensional characteristics of the specimens tested in static regime under three - point bending.

In figure 1 it can be seen the organization of the static tests under three - point bending of the CFRP-Nomex specimens.

\section{Flatwise compression test of sandwich specimens}

The compression tests were performed on five specimens of CFRP-Nomex sandwich structure using the universal testing machine WDW-150S type (fig. 2). The dimensions of the specimens tested in flatwise compression is in accordance with MIL-STD-401B Sec.5.2.4. The purpose of these tests is to determine the compression's basic properties (flatwise compressive strength and modulus) of the CFRP-Nomex sandwich panels. The typical specimen for this type of test is a $5 \mathrm{~cm}$ $x 5 \mathrm{~cm}$ panel, tested with a constant cross-head speed of $3 \mathrm{~mm} / \mathrm{min}$.

\section{Analysis of Charpy impact testing}

Ten specimens were tested for impact shock on samples unnotched using a Charpy hammer. The impact test samples of honeycomb sandwich panels are prepared according to the required dimension following the ISO 1791 standard (table 2).

For specimens without notch, the Charpy impact strength, $a_{c u^{\prime}}$ expressed in $\mathrm{kJ} / \mathrm{m}^{2}$ is determined by relation (1):

$$
a_{c U}=\frac{E_{c}}{d \cdot b} \cdot 10^{3}\left[\mathrm{~kJ} / \mathrm{m}^{2}\right],
$$

where: $E_{c}$ is the energy in joules, absorbed by breaking the test specimen of CFRP-Nomex; $d$ is the thickness, in millimetres, of the test specimen of CFRP-Nomex; $b$ is the width, in millimetres, of the testspecimen of CFRP-Nomex.

\section{Three-point bending fatigue test}

For most composite structures it is estimated a high reliability, determining the fatigue life under normal stress, requires a longer testing. For this reason, is opted for accelerated testing techniques. These types of tests are performed for more intensive stress regimes, compared with the normal stress regime, aimed for the intensification of the degradation process of composite materials and as an economic result shortening the time and costs related to testing. Within the accelerated tests are accepted the hypothesis that the rate of the processes' speed increases with increased stress. The CFRP-Nomex specimens used for three - point bending fatigue tests complied with the

Table 1

THE DIMENSIONS OF THE SPECIMENS USED IN STATIC BENDING TESTS

\begin{tabular}{|l|c|c|c|c|c|c|}
\hline Material & $\begin{array}{c}\text { Length } \\
\mathrm{mm}\end{array}$ & $\begin{array}{c}\text { Thickness } \\
\mathrm{mm}\end{array}$ & $\begin{array}{c}\text { Width } \\
\mathrm{mm}\end{array}$ & $\begin{array}{c}\text { Span length } \\
\mathrm{mm}\end{array}$ & $\begin{array}{c}\text { Core thickness } \\
\mathrm{mm}\end{array}$ & $\begin{array}{c}\text { Facing thickness } \\
\mathrm{mm}\end{array}$ \\
\hline $\begin{array}{l}\text { CFRP- } \\
\text { Nomex }\end{array}$ & 160 & 9 & 16 & 110 & 8 & 0.5 \\
\hline
\end{tabular}

Table 2

THE DIMENSIONS OF THE SPECIMENS TESTED FOR CHARPY IMPACT TEST

\begin{tabular}{|c|c|c|c|}
\hline Material & Length, $\mathrm{mm}$ & Thickness, $\mathrm{mm}$ & Width, $\mathrm{mm}$ \\
\hline CFRP-Nomex & 150 & 9 & 10 \\
\hline
\end{tabular}

Table 3

THE SPECIMEN DIMENSIONS SUBJECTED TO THREE - POINT BENDING FATIGUE TEST

\begin{tabular}{|c|c|c|c|}
\hline Material & Length, $\mathrm{mm}$ & Thickness, $\mathrm{mm}$ & Width, $\mathrm{mm}$ \\
\hline CFRP-Nomex & 200 & 9 & 20 \\
\hline
\end{tabular}


MIL-STD-401B Sec.5.3 methodology and has the following dimensions (table 3 ).

Accelerated fatigue bending tests were performed at three frequency regimens: $2.5 \mathrm{~Hz}, 3 \mathrm{~Hz}$ and $3.5 \mathrm{~Hz}$ and the data resulted from the accelerated tests were extrapolated for the normal test of $1.5 \mathrm{~Hz}$. At the three accelerated levels $(2.5 \mathrm{~Hz}, 3 \mathrm{~Hz}$ and $3.5 \mathrm{~Hz}$ ) were tested, in three - point bending fatigue, five specimens of CFRP-Nomex sandwich structure.

\section{Results and discussions}

Static three - point bending test of the CFRP-Nomex specimens

Ten specimens taken from the sandwich structure CFRP-Nomex - were tested under three-pointbending, until the appearance of fracture. With the help of the corresponding universal testing machine WDW-150S software was determined the load - displacement curves and the mechanical characteristics of the analyzed sandwich structures. For specimens tested were plotted the load - displacement curves by averaging these values for CFRP-Nomex specimens. This characteristic load displacement curve was represented in graphical form in figure 3 for CFRP-Nomex sandwich structures $[17,18]$.

The behaviour in terms of force and displacement of the ten specimens in static bending shows a linear relationship between the applied force and the displacement increase and then a decrease in the maximum force at the time of breaking of the specimen. The maximum force at which the irreversible damage to the analyzed sandwich structure material appeared was about $170 \mathrm{~N}$ for CFRP-Nomex specimens. Following the three - point bending tests resulted also the maximum deformations so that the value of the deformation for CFRP-Nomex sandwich specimens at maximum force was $3.5 \mathrm{~mm}$. Were analyzed specimens tested in three - point bending and it was found that the bonding between the CFRP skin and the Nomex honeycomb core showed no problems, so that the specimens' failure occurred on the entire sandwich surface, without delamination of the skin. The universal machine's testing program determined, on the basis of the CFRPNomex specimen's size and by setting the type test, the mechanical characteristics such as bending strength and bending modulus (fig. 4).

For bending strength values and bending modulus of elasticity in static three - point bending regime of the CFRPNomex specimens, the main statistical indicators were calculated (table 4 ). If the variation coefficient $(\delta)$ is close to zero $(\delta<30 \%)$, then the statistically computed data (coefficient of variation $\delta$ is in the range 5.7 to $11.5 \%$ ) are homogenous and the calculated mean is representative for these sets of values.

\section{Flatwise compressive properties of the CFRP-Nomex sandwich}

Ten specimens were subjected to flatwise compression and were experimentally determined using the data analysis program specific to the flatwise compressive

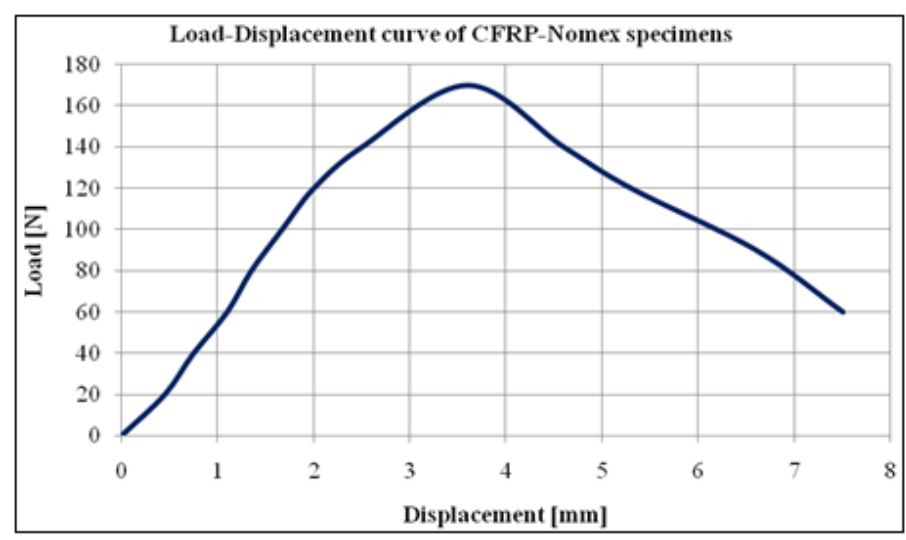

Fig. 3. Load-displacement static bending behavior of the CFRP-Nomex specimens

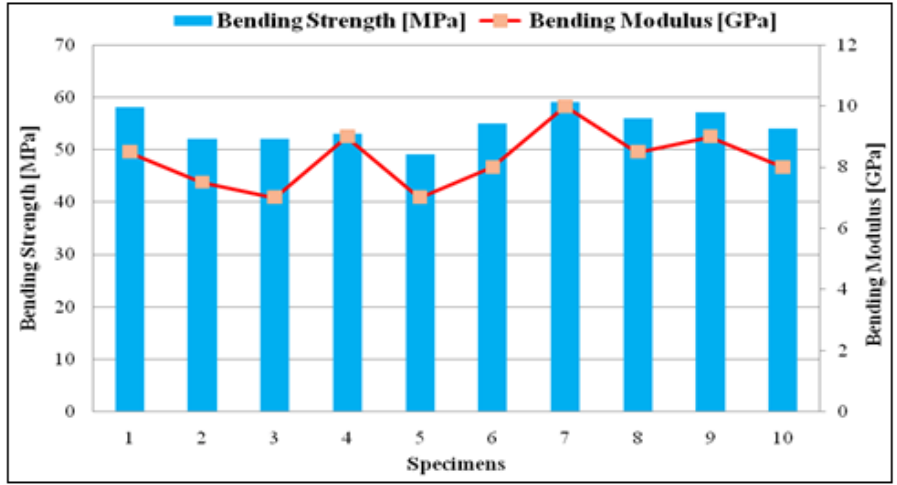

Fig. 4. Bending strength and bending modulus of the CFRP-Nomex specimens

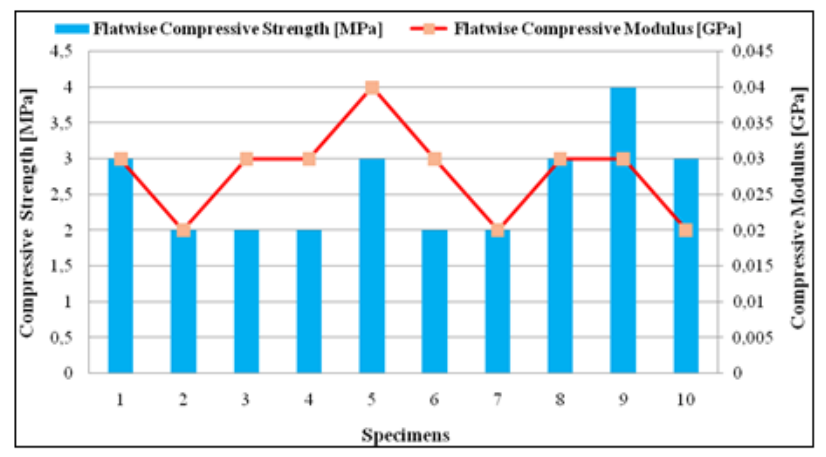

Fig. 5. Flatwise compressive strength and flatwise compressive modulus of the CFRP-Nomex specimens

Table 4

THE STATISTICAL INDICATORS DETERMINED AFTER THREE - POINT STATIC BENDING TESTS FOR CFRP-NOMEX SPECIMENS

\begin{tabular}{|c|c|c|c|}
\hline Material & $\begin{array}{c}\text { Mean } \\
(\mu)\end{array}$ & $\begin{array}{c}\text { Standard deviation } \\
(\mathrm{s})\end{array}$ & $\begin{array}{c}\text { Coefficient of variation } \\
(\delta) \%\end{array}$ \\
\hline $\begin{array}{c}\text { CFRP-Nomex - } \\
\text { Bending Strength (MPa) }\end{array}$ & 54.4 & 3.1 & 5.7 \\
\hline $\begin{array}{c}\text { CFRP-Nomex - } \\
\text { Bending Modulus (GPa) }\end{array}$ & 8.3 & 1 & 11.5 \\
\hline
\end{tabular}


Table 5

THE STATISTICAL INDICATORS DETERMINED DURING THE FLATWISE COMPRESSION TESTS OF THE CFRP-NOMEX SPECIMENS

\begin{tabular}{|c|c|c|c|}
\hline Material & $\begin{array}{c}\text { Mean } \\
(\mu)\end{array}$ & $\begin{array}{c}\text { Standard deviation } \\
(s)\end{array}$ & $\begin{array}{c}\text { Coefficient of variation } \\
(\delta) \%\end{array}$ \\
\hline $\begin{array}{c}\text { CFRP-Nomex - } \\
\text { Flatwise compressive strength (MPa) }\end{array}$ & 2.6 & 0.7 & 27 \\
\hline $\begin{array}{c}\text { CFRP-Nomex - } \\
\text { Flatwise compressive modulus (GPa) }\end{array}$ & 0.028 & 0.01 & 22 \\
\hline
\end{tabular}

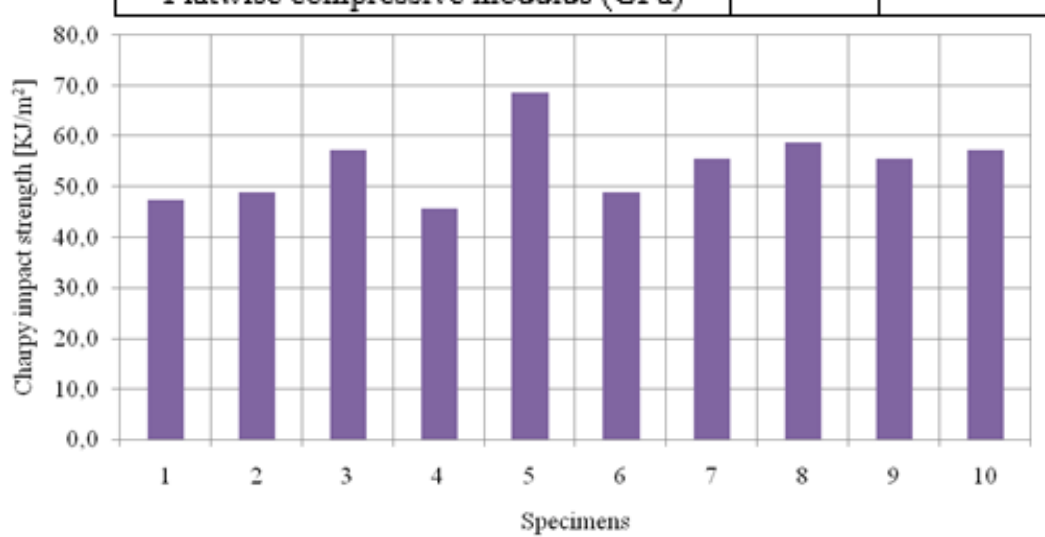

Fig. 6. Impact strengths of the CFRP-Nomex specimens

Table 7

HE COMPUTING OF THE NUMBER OF CYCLES TO FAILURE FOR THE NORMAL LEVEL TEST (1.5 HZ LOADING FREQUENCY) OF THE NOMEX-CFRP SPECIMENS

\begin{tabular}{|c|c|c|c|c|}
\hline $\begin{array}{c}\text { Specimen } \\
\text { No. }\end{array}$ & $\begin{array}{c}\text { The number of cycles to } \\
\text { failure in accelerated } \\
\text { conditions }\end{array}$ & $\begin{array}{c}\text { Accelerated } \\
\text { Frequency Level } \\
{[\mathrm{Hz}]}\end{array}$ & $\begin{array}{l}\text { Acceleration } \\
\text { factor }\end{array}$ & $\begin{array}{c}\text { The number of cycles to } \\
\text { failure in normal } \\
\text { conditions }\end{array}$ \\
\hline 1 & 31826 & \multirow{5}{*}{2.5} & \multirow{5}{*}{8.13} & 259047 \\
\hline 2 & 32015 & & & 260586 \\
\hline 3 & 34699 & & & 282432 \\
\hline 4 & 35798 & & & 291377 \\
\hline 5 & 36619 & & & 298060 \\
\hline 6 & 15052 & \multirow{5}{*}{3} & \multirow{5}{*}{17.2} & 258939 \\
\hline 7 & 15301 & & & 263222 \\
\hline 8 & 15471 & & & 266147 \\
\hline 9 & 16730 & & & 287805 \\
\hline 10 & 16999 & & & 292433 \\
\hline 11 & 6199 & \multirow{5}{*}{3.5} & \multirow{5}{*}{33.38} & 200777 \\
\hline 12 & 7237 & & & 234396 \\
\hline 13 & 7360 & & & 238380 \\
\hline 14 & 8556 & & & 277117 \\
\hline 15 & 9867 & & & 319578 \\
\hline
\end{tabular}

strength and compressive modulus flatwise testing machine (fig. 5). Flatwise compression strength values are between 2 and $4 \mathrm{MPa}$ and the elasticity modulus takes values ranging from 0.02 to $0.04 \mathrm{GPa}$.

For the ten values obtained for flatwise compressive strength and flatw ise compressive modulus CFRP-Nomex specimens were determined the most representative statistical indicators (table 5 ).

The determined values of the coefficient of variation is below the $30 \%$, so it can be concluded that the sample with ten specimens (tested for flatwise compression) analysed is a homogeneous one and at the same time, the mean values for flatwise compressive strength and flatwise compressive modulus is representative in statistical terms.

\section{Charpy impact test results}

To appreciate the tenacity of CFRP-Nomex sandwich structure impact tests were made using the Charpy hammer. The mean impact strength of CFRP-Nomex sandwich specimens was $54.4 \mathrm{~kJ} / \mathrm{m}^{2}$. The specimens were tested for impact and it was observed that all of the ten specimens occur a complete fracture, of the without delamination or cracking of the skins and the Nomex honeycomb core. In figure 6 were described the values for the impact strength of the ten CFRP-Nomex unnotched specimens, which were determined using the relation 1.

Accelerated bending fatigue test of the CFRP-Nomex specimens

Increasing global competition has led manufacturers to develop multiple products with features and high reliability, at a low price, in a short time. Difficulties posed by these goals have motivated the manufacturers to develop and use effective reliability methods including accelerated tests. Acceleration tests are a way to expedite the acquisition of information on product performance in terms 


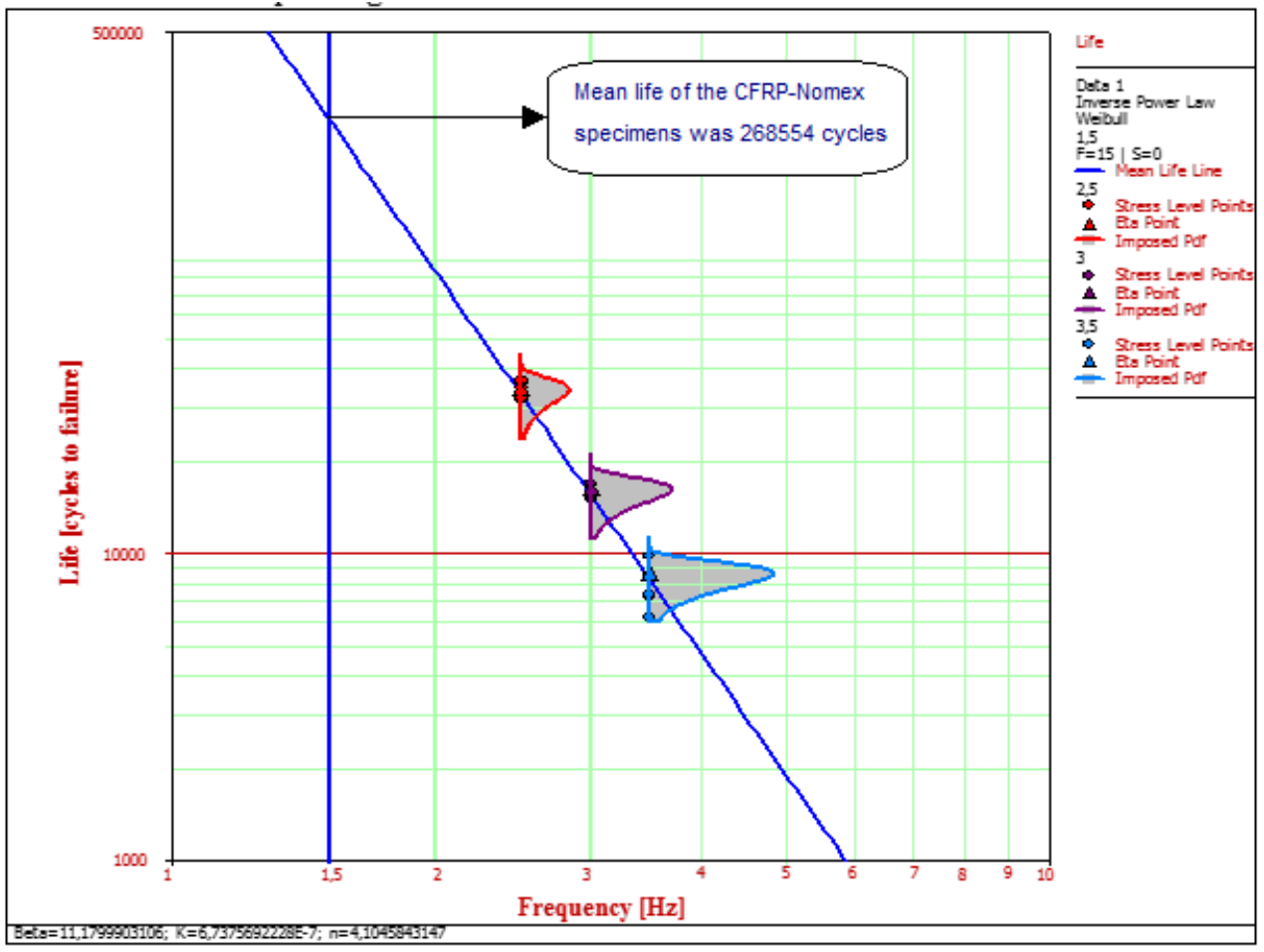

Fig. 7. The graphic determination of the mean number of cycles to

failure of the CFRP-Nomex specimens

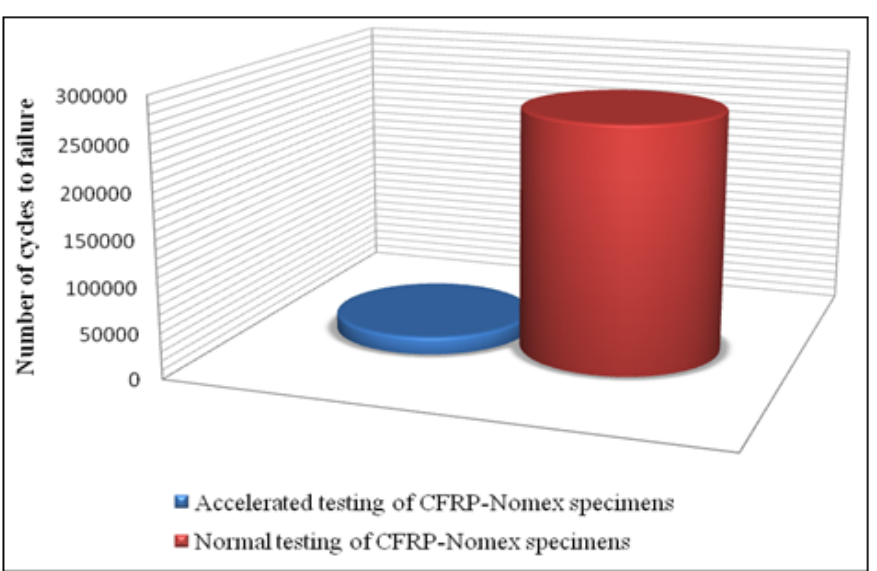

Fig. 8. The graphical comparison between the total number of cycles to failure in the accelerated regime and the total number of cycles to failure in the normal regime of CFRP-Nomex specimens

of economic efficiency [15]. Accelerating the operating conditions, meaning the time compression test, can be studied also as a function of the number of cycles to failure. Through accelerated methods the use regime is forced, due to the increased rate and/or stress level to which the product undergoes. Such methods, which actually cause aging processes or premature wear, must cause the increase of the degradation rate, but without changing the physical character of the wear process (without causing damage that is not typical to the normal operation).

In this paper it was proposed a methodology for accelerated testing of CFRP-Nomex specimens, which is to accelerate the test level compared to the normal regime test $(1.5 \mathrm{~Hz})$, with the aim of enhancing the degradation processes of the composite sandwich structures. In the three - point bending loadings were tested fifteen specimens at three accelerated testing regimes: $2.5 \mathrm{~Hz}, 3$ $\mathrm{Hz}$ and $3.5 \mathrm{~Hz}$. Using the acceleration methodology, were obtained, as a result of the three - point bending fatigue tests, the number of cycles to failure for each tested specimen. These results (number of cycles to failure) obtained from the accelerated tests, were extrapolated to the normal test of $1.5 \mathrm{~Hz}$ using statistical processing of experimental data with the help of the ALTA 9-Accelerated Life Testing Analysis program. For statistical analysis of experimental data it was used the Inverse Power Law model and Weibull distribution. The experimental data were introduced in ALTA 9 - Accelerated Life Testing Analysis and the statistical analysis yielded the following values of the parameters for the Inverse Power Law Weibull model: $\beta=11.18 ; k=0.0000007 ; n=4.105$.

The number of cycles to failure in normal testing regime for CFRP-Nomex specimens is determined as the multiplication between the number of cycles to failure in accelerated conditions and the accelerating factor (table 6). The number of cycles to failure in normal test regime corresponds to the Inverse Power Law - Weibull model.

The main objective of the accelerated tests is to quantitatively determine the life in normal testregime [16]. Using data resulted from accelerated fatigue tests using three - point bending tests, it can be determined the mean number of cycles to failure of CFRP-Nomex specimens to the normal test regime (on loading frequency $1.5 \mathrm{~Hz}$ ). The principle on which the extrapolation of the accelerated test results is done for CFRP-Nomex specimens is represented in figure 7 . Using data obtained from the 3 levels of accelerated stress $(2.5 \mathrm{~Hz}, 3 \mathrm{~Hz}$ and $3.5 \mathrm{~Hz})$ and using the acceleration law of the Inverse Power Law model, the results from accelerated testing were extrapolated in normal testing regime. The results' extrapolation comprises of the following steps: determining the mean values for the three levels of operation of the accelerated stress $\left(m_{1}, m_{2}, m_{3}\right)$; through these points plot a straight line; by the extension of the straight line to the required normal value $(1.5 \mathrm{~Hz})$ the mean lifetime in normal specimens testing of CFRP-Nomex can be determined. The mean number of cycles to failure under normal test conditions $(1.5 \mathrm{~Hz})$ is determined using the appropriate mean relation corresponding to the Inverse Power Law - Weibull model and is 268554.

\section{Conclusions}

In this paper it was presented an experimental analysis on the fatigue properties of CFRP-Nomex sandwich structures tested in three - point bending in static and dynamic regime at different frequency levels. Also, were analyzed the mechanical characteristics on compression and Charpy impact of the CFRP-Nomex specimens. 
Following the tests were determined the mechanical properties of CFRP-Nomex structures, (bending strength, bending modulus, flatwise compressive strength, flatwise compressive modulus, impact strength).

By implementing accelerated fatigue testing methodologies of the CFRP-Nomex sandwich specimens it was significantly reduced the testing time. For the examined case study, in figure 8 are cumulated numbers of cycles to failure of the accelerated tests and from the normal regime testing. It can be seen that by using accelerated fatigue tests on CFRP-Nomex specimens, the testing time is reduced by 13.9 times. This result leads to major reductions in the cost of testing products that have a lifespan as long as possible. Given the fierce competition in the composite material industry's market and taking into account the reduction of test time obtained in this paper, many companies will implement and develop such accelerated techniques to obtain in the fastest way possible the information regarding the lifetime and fatigue behaviour.

Acknowledgements: We hereby acknowledge the structural founds projectPRO-DD (POS-CCE, 0.2.2.1., ID 123, SMIS2637, ctr. No 11/2009) for providing the infrastructure used in this work.

\section{References}

1. MANES, A., GILIOLI, A., SBARUFATTI, C., GIGLIO, M., Compos. Struct., 99, 2013, p. 8

2. LIU, L., WANG, H., GUAN. Z., Compos. Struct., 121, 2015, p. 304

3. KOOTSOOKOS, A., BURCHILL, P. J., Compos. Part A-Appl. S., 35, no. 4, 2004, p. 501
4. CONSTANTIN, F., MILLET, J. P., ABRUDEANU, M., IONESCU, C., Rev. Chim. (Bucharest), 62, no. 12, 2011, p. 1157

5. ZHOU, G., HILL, M., HOOKHAM, N., J. Sandwich Struct. Mater., 9, 2007, p. 309

6. BENTOUHAMI, A., KESKES, B., Mater. Tehnol., 49, no. 2, 2015, p. 235

7. KANNY, K., MAHFUZ, H., Compos. Struct., 67, no. 4, 2005, p. 403

8. CODYRE, L., FAM, A., Compos. Part B - Eng., 106, 2016, p. 129

9. ROY, R., NGUYEN, K. H., PARK, Y. B., KWEON, J. H., CHOI, J. H., Compos. Part B-Eng., 56, 2014, 762

10. LIU, L., MENG, P., WANG. H., GUAN, Z., Compos. Part B - Eng., 76, 2015, p. 122

11. GILIOLI, A., SBARUFATTI, C., MANES, A., GIGLIO, M., Compos. Part B - Eng., 67, 2014, p. 313

12. GIGLIO, M., GILIOLI, A., MANES, A., Comput. Mater. Sci., 56, 2012, p. 69

13. BOUKHAROUBA, W. BEZAZI A., SCARPA, F., Measurement, 53, 2014, p. 161

14. CAI, G. M., WANG, X. G., SHI, X. J., YU, W. D., J. Compos. Mater., 46, no. 7, 2012, p. 833

15. ZAHARIA, S. M., MARTINESCU, I., Teh Vjesn., 23, no. 5, 2016, p. 1447

16.ZAHARIA, S. M., MARTINESCU, I., MORARIU, C. O., Eksploat. Niezawodn., 14, no. 2, 2012, p. 99

17. COTERLICI, R. F., GEAMAN, V., POP,M. A., BEDO, T., RADOMIR, I., CHIVU,O.R., FLOREA, B., SEMENESCU, A., Rev. Chim.(Bucharest), 67, no. 10, 2016,p. 2049

18. GEAMAN, V., POP, M.A., RADOMIR, I.,BEDO1, FLOREA, T.B., SEMENESCU, A., CHIVU, A.R., PASARE, M., GLIGOR, A. M., Rev. Chim.(Bucharest), 67, no. 11, 2016, p. 2207

$\overline{\text { Manuscript received: } 15.02 .2017}$ 